\title{
Cardiac Rehabilitation After Acute Myocardial Infarction Resuscitated From Cardiac Arrest
}

\author{
Chul Kim, MD, PhD ${ }^{1}$, Heejin Jung, MD ${ }^{1}$, Hee Eun Choi, MD², Seong Hoon Kang, MD ${ }^{1}$ \\ ${ }^{1}$ Department of Rehabilitation Medicine, Inje University Sanggye Paik Hospital, Seoul; \\ ${ }^{2}$ Department of Rehabilitation Medicine, Inje University Haeundae Paik Hospital, Busan, Korea
}

\begin{abstract}
Objective To examine the safety and effectiveness of cardiac rehabilitation on patients resuscitated from cardiac arrest due to acute myocardial infarction.

Methods The study included 23 subjects, including 8 with history of cardiac arrest and 15 without history of cardiac arrest. Both groups underwent initial graded exercise test (GXT) and subsequent cardiac rehabilitation for 6 weeks. After 6 weeks, both groups received follow-up GXT.

Results Statistically significant $(\mathrm{p}<0.05)$ increase of $\mathrm{VO}_{2 \text { peak }}$ and maximal $\mathrm{MVO}_{2}$ but significant $(\mathrm{p}<0.05)$ decrease of submaximal $\mathrm{MVO}_{2}$ and resting heart rate were observed in both groups after 6 weeks of cardiac rehabilitation. An increasing trend of maximal heart rates was observed in both groups. However, the increase was not statistically significant ( $\mathrm{p}>0.05)$. There was no statistically significant change of resting heart rate, maximal heart rate, maximal $\mathrm{MVO}_{2}$, or submaximal $\mathrm{MVO}_{2}$ in both groups after cardiac rehabilitation. Fatal cardiac complications, such as abnormal ECG, cardiac arrest, death or myocardial infarction, were not observed. All subjects finished the cardiac rehabilitation program

Conclusion Improvement was observed in the exercise capacity of patients after aerobic exercise throughout the cardiac rehabilitation program. Therefore, cardiac rehabilitation can be safely administered for high-risk patients with history of cardiac arrest. Similar improvement in exercise capacity can be expected in patients without cardiac arrest experience.
\end{abstract}

Keywords Cardiac arrest, Myocardial infarction, Rehabilitation

Received February 7, 2014; Accepted July 21, 2014

Corresponding author: Heejin Jung

Department of Rehabilitation Medicine, Sanggye Paik Hospital, Inje University College of Medicine, 1342 Dongil-ro, Nowon-gu, Seoul 139707, Korea

Tel: +82-2-950-1134, Fax: +82-2-935-3076, E-mail: s3034@paik.ac.kr

(c) This is an open-access article distributed under the terms of the Creative Commons Attribution Non-Commercial License (http://creativecommons. org/licenses/by-nc/3.0) which permits unrestricted noncommercial use, distribution, and reproduction in any medium, provided the original work is properly cited.

Copyright $\odot 2014$ by Korean Academy of Rehabilitation Medicine

\section{INTRODUCTION}

A cardiac arrest refers to the state when mechanical heart pumps activity stops and oxygen cannot be delivered to organs [1]. In adults, the most common causes of cardiac arrest are coronary artery diseases (CADs) [2], which are mostly accompanied by ventricular fibrillation [3]. Due to recent improvements in emergency medical technology, there has been an increase in the number of patients resuscitated from cardiac arrest, including those who received percutaneous coronary intervention with positive clinical outcomes [4]. Although the survival rate 
after cardiac arrest from myocardial infarction (MI) is increasing $[5,6]$, the decline in motor and psychological functions can reduce patients' quality of life [7]. Therefore, active cardiac rehabilitation must be accompanied by treatment for underlying diseases in order to restore all functions back to the level before the cardiac arrest [8].

Cardiac rehabilitation plays a critical role in the management of risk factors for CAD [9]. Cardiac rehabilitation is known to decrease the mortality related to cardiac disease by $20 \%$ with the improvement of heart and lung function, socio-psychological status, and the quality of life. In addition, it delays the progression of atherosclerosis and decreases its severity [9-11].

Recently, the utility of cardiac rehabilitation has been actively studied in CAD patients [9]. However, no research study has been performed regarding the stability and effectiveness of cardiac rehabilitation on patients with severe MI comorbidities, such as cardiac arrest. Therefore, the objective of this study was to determine the safety and effectiveness of cardiac rehabilitation on patients with CAD who have been resuscitated from cardiac arrest. These subjects are known to have high risk for cardiac rehabilitation.

\section{MATERIALS AND METHODS}

\section{Subjects}

The study subjects were patients who visited the Sanggye Paik Hospital emergency room between August 2010 and August 2013 due to cardiac arrest. Cardiac arrest was defined as ventricular fibrillation, pulseless electrical activity, or asystole. Subjects were resuscitated and received successful percutaneous coronary intervention (PCI) for acute MI. These subjects were referred as the cardiac arrest group. Patients who received PCI for acute MI without cardiac arrest were also included in the study. These subjects were referred as the non-cardiac arrest group. In this study, the safety of cardiac rehabilitation and the effectiveness of aerobic exercise were studied on these two groups. The exclusion criteria were as follows: inability to carry out the exercise program, history of heart failure, valvular heart diseases, left ventricular ejection fraction (LVEF) less than $40 \%$ on echocardiography (ECG), cerebrovascular diseases, neuromuscular disorders, and musculoskeletal pain. This research was done retrospectively by analyzing medical records. The study was reviewed and approved by the Institutional Review Board.

\section{Methods}

All patients in the cardiac arrest group or the noncardiac arrest group were discharged from the hospital after PCI. They received orientation regarding the necessity and contents of the cardiac rehabilitation program. Graded exercise test (GXT) was performed on their first visit at the cardiac rehabilitation clinic.

For GXT, the symptom limited method by modified Bruce protocol was used according to the American Association of Cardiovascular and Pulmonary Rehabilitation (AACVPR) guidelines. GXT measures $\mathrm{VO}_{2 \max }$, duration of exercise, and submaximal rate pressure product $\left(\mathrm{RPP}_{\text {submax }}\right)$. The maximal oxygen uptake $\left(\mathrm{VO}_{2 \max }\right)$ was defined as the highest value or the plateau of directly measured oxygen consumption using a respiratory gas analyzer (QMC; Quinton Instrument Co., Boston, MA, USA). The duration of exercise was defined as the maximal exercising time during GXT. The RPP $\mathrm{Pubmax}_{\text {was }}$ walculated by multiplying the heart rate and systolic blood pressure values obtained at the second minute of the third stage of modified Bruce protocol. The target heart rate was calculated according to the Karvonen formula: [(maximal heart rate - resting heart rate $\times \%$ exercise intensity) + resting heart rate]. The target heart rate was calculated at $60 \%$ of the maximal heart rate during the first two weeks, at $70 \%$ during the third and fourth weeks, and at $85 \%$ during the fifth and sixth weeks. A wireless ECG monitoring system (Q-Tel ECG telemetry system, Quinton Instrument Co.) was used to monitor possible abnormal ECG (myocardial ischemia or arrhythmia) and heart rates. Patients were subjectively rated on Borg's rate of perceived exertion (RPE). Patients participated in 50-minute exercise programs three times a week for 6 weeks for a total of 18 exercises. Each session consisted of 10 minutes warm-up, 30 minutes main exercise, and 10 minutes cool down. The main exercise consisted of 15 minutes of treadmill and 15 minutes of ergometer. After completion of 6 weeks' hospital-based cardiac rehabilitation training, exercise was continued at home according to the instruction with the intensity of $60 \%$ of the heart rate reserve in both groups. As CAD risk factor control, patients got diet therapy education, nutrition consultation and smoking cessation lecture. They also received drug treatment from a cardiologist for their 
high blood pressure, diabetes, or dyslipidemia. CAD risk factors were continuously evaluated through follow-up in outpatient clinic and strictly controlled through education for lifestyle modification. After 6 weeks of cardiac rehabilitation program, patients in both groups underwent exercise test to evaluation the exercise capacity improvement.

\section{Statistical analysis}

To compare age, diagnosis, and early $\mathrm{VO}_{2 \text { peak }}$ between both groups, Mann-Whitney U test was used. To compare sex, smoking history, location of stent insertion, currently taking medications, and risk factors for CAD, Pearson chi-square test and Fisher exact test were used. To compare the effects of exercise between the two groups, Wilcoxon signed-rank test and Mann-Whitney U test were used to compare the amount of changes in $\mathrm{VO}_{2 \text { peak }}$, $\mathrm{HR}_{\text {rest }}, \mathrm{HR}_{\text {max }}$ and RPP between the two groups. SPSS ver. 18 (SPSS Inc., Chicago, IL, USA) was used for all statistical analysis. Statistical significance was defined as $\mathrm{p}<0.05$.

\section{RESULTS}

\section{Characteristics of the study subjects}

The study included 23 subjects consisting of 8 patients with history of cardiac arrest and 15 patients without such history. The cardiac arrest group consisted of 7 males and 1 female. The non-cardiac arrest group consisted of 13 males and 2 females. There was no difference regarding the distribution of sex in the two groups. The average age of the patients in the cardiac arrest group and the noncardiac arrest group was 46.7 and 51.2 years, respectively, which were not significantly different. The cardiac arrest group visited the cardiac rehabilitation clinic for the first time on average of 25.6 days after the PCI to undergo the exercise test. The non-cardiac arrest group visited the cardiac rehabilitation clinic for the first time on average of 15 days after the PCI to undergo the exercise test. No statistically significant differences were found in the distribution of this classification or the numbers of blood vessels with stent insertion. Furthermore, there were no statistically significant differences in LVEF, risk factors (hypertension, diabetes, dyslipidemia, smoking status, and body mass index), or drug taken (Table 1).
Table 1. Demographic data of study subjects

\begin{tabular}{|c|c|c|c|}
\hline & Arrest (+) & Arrest (-) & p-value \\
\hline Gender (male:female) & $7: 1$ & $13: 2$ & 0.955 \\
\hline Age (yr) & $46.75 \pm 11.08$ & $51.20 \pm 11.97$ & 0.605 \\
\hline Clinical diagnosis & & & 0.685 \\
\hline NSTEMI & $4(50.0)$ & $6(40.0)$ & \\
\hline STEMI & $4(50.0)$ & $9(60.0)$ & \\
\hline \multicolumn{4}{|c|}{ Number of involved vessel } \\
\hline 1 & $5(62.5)$ & $10(66.6)$ & 0.596 \\
\hline 2 & $3(37.5)$ & $4(26.6)$ & 0.467 \\
\hline 3 & $0(0)$ & $1(6.7)$ & 0.652 \\
\hline Duration of CR (hr) & 18 & 18 & 1 \\
\hline Hypertension & $4(50.0)$ & $8(53.0)$ & 0.879 \\
\hline Diabetes & $4(50.0)$ & $5(33.0)$ & 0.657 \\
\hline Dyslipidemia & $6(75.0)$ & $12(80.0)$ & 0.782 \\
\hline \multicolumn{4}{|l|}{ History of smoking } \\
\hline Never & $3(37.5)$ & $6(40.0)$ & 0.633 \\
\hline Current smoker & $5(62.5)$ & $6(40.0)$ & 0.278 \\
\hline Ex-smoker & 0 & $3(20.0)$ & 0.2257 \\
\hline BMI $\left(\mathrm{kg} / \mathrm{m}^{2}\right)$ & $23.58 \pm 2.20$ & $25.28 \pm 3.55$ & 0.186 \\
\hline LVEF & $51.50 \pm 7.57$ & $45.85 \pm 9.97$ & 0.114 \\
\hline $\mathrm{VO}_{2 \text { peak }}$ & $25.57 \pm 9.69$ & $30.63 \pm 6.10$ & 0.210 \\
\hline hsCRP & $0.26 \pm 0.25$ & $0.38 \pm 0.75$ & 0.846 \\
\hline HbAlc & $6.35 \pm 0.81$ & $6.74 \pm 1.73$ & 0.974 \\
\hline \multicolumn{4}{|l|}{ Current medication } \\
\hline ACEi & $4(50.0)$ & $4(26.0)$ & 0.371 \\
\hline ARB & $1(12.5)$ & $2(13.3)$ & 0.955 \\
\hline$+\mathrm{CCB}$ & 0 & $2(13.3)$ & 0.526 \\
\hline A,B-blocker & $3(37.5)$ & $7(46.7)$ & 0.673 \\
\hline B-blocker & $4(50.0)$ & $2(13.3)$ & 0.056 \\
\hline Statins & $7(87.5)$ & $14(93.3)$ & 0.955 \\
\hline Diuretics & $2(25.0)$ & $3(20.0)$ & 0.782 \\
\hline Nitrates & $5(62.5)$ & $8(53.3)$ & 0.673 \\
\hline Aspirin & $8(100)$ & $15(100)$ & 1 \\
\hline Clopidogrel & $8(100)$ & $15(100)$ & 1 \\
\hline
\end{tabular}

Values are presented as mean \pm standard deviation or number (\%).

NSTEMI, non-ST elevation myocardial infarction; STEMI, ST elevation myocardial infarction; CR, cardiac rehabilitation; BMI, body mass index; LVEF, left ventricle ejection fraction; $\mathrm{VO}_{2 \text { peak }}$, peak oxygen consumption; hsCRP, high sensitivity $\mathrm{C}$ reactive protein; HbAlc, hemoglobin Alc; ACEi, angiotensin converting enzyme inhibitor; $\mathrm{ARB}$, angiotensin receptor blocker; $\mathrm{CCB}$, calcium channel blocker. 
Table 2. Comparison before and after the cardiac rehabilitation program

\begin{tabular}{lccccc}
\hline & \multicolumn{2}{c}{ Arrest (+) } & \multicolumn{2}{c}{ Arrest (-) } \\
\cline { 2 - 3 } \cline { 5 - 6 } & \multicolumn{1}{c}{ Before CR } & After CR & & Before CR & After CR \\
\hline $\mathrm{VO}_{\text {2peak }}(\mathrm{mL} / \mathrm{kg} / \mathrm{min})$ & $25.5 \pm 9.6$ & $32.9 \pm 8.4^{*}$ & & $30.6 \pm 6.1$ & $35.0 \pm 8.7^{*}$ \\
$\mathrm{RPP}_{\text {max }}$ & $23,776.0 \pm 5,715.8$ & $26,934.4 \pm 5,171.1^{*}$ & & $22,577.0 \pm 5,733.8$ & $25,407.5 \pm 5,017.8$ \\
$\mathrm{RPP}_{\text {submax }}$ & $13,624.1 \pm 3,245.9$ & $11,382.1 \pm 1,679.1^{*}$ & & $14,534.6 \pm 3,201.9$ & $11,429.2 \pm 2,859.3^{*}$ \\
$\mathrm{HR}_{\text {rest }}$ & $74.8 \pm 9.4$ & $68.2 \pm 9.6^{*}$ & & $74.3 \pm 10.7$ & $67.0 \pm 11.6^{*}$ \\
$\mathrm{HR}_{\text {max }}$ & $138.2 \pm 12.3$ & $151.8 \pm 5.9$ & & $157.6 \pm 16.0$ & $150.2 \pm 10.5$ \\
\hline Exercise duration & $13.7 \pm 2.9$ & $18.5 \pm 0.7^{*}$ & & $15.0 \pm 2.2$ & $19.3 \pm 9.9^{*}$ \\
\hline
\end{tabular}

Values are presented as mean \pm standard deviation.

$\mathrm{CR}$, cardiac rehabilitation; $\mathrm{HR}_{\max }$, maximal heart rate; $\mathrm{HR}_{\text {rest }}$, resting heart rate; $\mathrm{RPP}_{\max }$, maximal rate pressure product; $\mathrm{RPP}_{\text {submax }}$, submaximal rate pressure product at stage $3 ; \mathrm{VO}_{\text {2peak }}$, peak oxygen consumption.

${ }^{*} \mathrm{p}<0.05$ before vs. after cardiac rehabilitation.

\section{Cardiovascular-related complications during exercise mo-} nitoring

According to AACVPR guidelines on risk classification for exercise training, all subjects in the cardiac arrest group were in the high risk group [12,13]. In contrast, none of the subjects from the non-cardiac arrest group belonged to the high risk group. In this study, only two patients with intermittent ventricular premature contraction (VPC) were observed in the cardiac arrest group during exercise monitoring. However, it did not lead to any dangerous or critical condition. They were relieved without special treatment. No fatal cardiac complications, such as abnormal ECG, hemodynamic response, cardiac arrest, death or myocardial infarction, were observed. All 23 subjects finished the cardiac rehabilitation program.

Data comparison before and after the cardiac rehabilitation program

After 6 weeks of aerobic exercise according to the cardiac rehabilitation program, the $\mathrm{VO}_{2 \text { peak }}$ increased from the average of 25.5 to $32.9 \mathrm{~mL} / \mathrm{kg} / \mathrm{min}$ in the cardiac arrest group and from 30.6 to $35.0 \mathrm{~mL} / \mathrm{kg} / \mathrm{min}$ in the noncardiac arrest group. The increase was statistically significant $(\mathrm{p}<0.05)$ in both groups. Submaximal myocardial oxygen demand $\left(\mathrm{MVO}_{2}\right)$ and the resting heart rate were significantly $(\mathrm{p}<0.05)$ decreased in both groups. However, maximal $\mathrm{MVO}_{2}$ values were significantly $(\mathrm{p}<0.05)$ increased in both groups. Although the maximal heart rate showed an increasing trend, the increase was not statistically significant $(\mathrm{p}>0.05)$ (Table 2).
Table 3. Rate of change comparison between the two groups before and after the cardiac rehabilitation program (unit, \%)

\begin{tabular}{lcrc}
\hline & Arrest (+) & Arrest (-) & p-value* \\
\hline $\mathrm{VO}_{\text {2peak }}$ & $35.4 \pm 25.2$ & $12.1 \pm 20.9$ & 0.056 \\
$\mathrm{HR}_{\text {rest }}$ & $-8.7 \pm 9.8$ & $-9.8 \pm 11.3$ & 0.630 \\
$\mathrm{HR}_{\text {max }}$ & $10.4 \pm 8.9$ & $4.2 \pm 11.1$ & 0.267 \\
$\mathrm{RPP}_{\text {submax }}$ & $-17.0 \pm 16.4$ & $-20.2 \pm 16.3$ & 0.581 \\
$\mathrm{RPP}_{\text {max }}$ & $12.3 \pm 9.8$ & $16.9 \pm 25.9$ & 0.972 \\
\hline
\end{tabular}

Values are presented as mean \pm standard deviation.

$\mathrm{VO}_{\text {ppeak }}$, peak oxygen consumption; $\mathrm{HR}_{\max }$, maximal heart rate; $\mathrm{HR}_{\text {rest }}$, resting heart rate; $\mathrm{RPP}_{\text {submax }}$, submaximal rate pressure product at stage $3 ; \mathrm{RPP}_{\max }$, maximal rate pressure product.

${ }^{*} \mathrm{p}<0.05$ Arrest (+) vs. Arrest (-).

Changing rate $=(\mathrm{B}-\mathrm{A}) / \mathrm{A} \times 100 ; \mathrm{A}$, baseline before cardiac rehabilitation; $\mathrm{B}$, result after cardiac rehabilitation.

Rate of change comparison between the two groups before and after the cardiac rehabilitation program

No statistically significant ( $p>0.05$ ) differences were observed in resting heart rate change, maximal heart rate, maximal $\mathrm{MVO}_{2}$, or submaximal $\mathrm{MVO}_{2}$. The rate of change in $\mathrm{VO}_{2 \text { peak }}$ was 35.4 in the cardiac arrest group which was higher than the result of 12.1 in the non-cardiac arrest group. However, this difference was not statistically significant ( $p>0.05)$ (Table 3).

\section{DISCUSSION}

CAD with the inclusion of acute MI has a high prevalence and mortality rate worldwide. Although the mortal- 
ity rate is decreasing due to recent improvement in medical technology, the prevalence rate is steadily increasing $[14,15]$. Patients who are resuscitated from cardiac arrest show a decrease in exercise capacity and reduced quality of life as well as mental distress as a possible complication of acute MI, making it difficult to control the risk factors. It was reported in several previous studies that cardiac rehabilitation after acute MI plays an important role in the increased exercise capacity, the management of the risk factors, and the secondary prevention of CAD $[16,17]$. Cardiac rehabilitation is known to restore physical, mental, and social capabilities to the level prior to disease occurrence $[16,17]$.

This study revealed that the values of $\mathrm{VO}_{2 \text { peak }}$ and $\mathrm{MVO}_{2}$ at stage 3 were significantly increased and the resting heart rate were significantly decreased in both groups after cardiac rehabilitation, suggesting that exercise capacity can be increased after exercise training and cardiac rehabilitation program, even in high risk patients, such as patients from the cardiac arrest group. Particularly, the high increase of $\mathrm{VO}_{2 \text { peak }}$ which is closely related to the survival rate may be of great benefit for high risk patients. This result supports the beneficial effects of cardiac rehabilitation program for both groups.

Although there were no statistically significant differences in the change rates of $\mathrm{VO}_{2 \text { peak }}$ the change rate was $35.4 \%$ in the cardiac arrest group, which was much higher than $12.1 \%$ in the non-cardiac arrest group. Even though this difference was not significant, it may be due to a lower initial $\mathrm{VO}_{2 \text { peak }}$ of cardiac arrest group compared to that of the non-cardiac arrest group. This result is in consistent with previous studies that showed a higher increase in rate of in $\mathrm{VO}_{2 \text { peak }}$ was achieved after cardiac rehabilitation program when the initial $\mathrm{VO}_{\text {2peak }}$ was low [18].

In this study, similar results were obtained for other variables except the maximum heart rate which was affected by age. In both groups, the resting heart rate and the submaximal $\mathrm{MVO}_{2}$ decrease indicated that the whole body circulation was required to carry out the same intensity of exercise which consequently led to a decreased stress on the heart. In addition, maximal myocardial oxygen consumption increased after the cardiac rehabilitation program, indicating that the maximum intensity of exercise tolerated by patients has increased.

The cardiac arrest group was considered to have a high risk of cardiovascular complication during exercise in this study. However, during the monitoring exercise, only 3 events of intermittent VPC were observed out of 144 hours. They were relieved without additional treatment. No fatal cardiovascular complication was observed, suggesting that careful monitoring during exercises and prescription of suitable exercise program can effectively decrease the risk and fear of exercise related complications. Therefore, cardiac rehabilitation can be actively applied to high risk patients.

The limitations of this study were as follows. Firstly, the number of subjects was too small. Secondly, there were more males than females in both groups. In previous studies, the proportion of female participants in cardiac rehabilitation after PCI was about 7\%-20\% [19]. In this study, a similar rate of participation was observed in both genders. Further studies comparing male and female patients may be needed by inclusion of more female subjects. Thirdly, this study did not conduct a longer followup after 6 weeks. Therefore, long-term improvement in exercise capacity after the 6 weeks of cardiac rehabilitation program could not be confirmed.

Despite these limitations, this study safely implemented aerobic exercise in patients of the cardiac arrest group in the cardiac rehabilitation program. Appropriate monitoring was conducted. Strong improvement in exercise capacity was observed in both groups.

In conclusion, the exercise capacity in both study groups was increased after the aerobic exercise in the cardiac rehabilitation program. There were no statistically significant differences between the two groups in the rate of improvement. Considering this result, the cardiac rehabilitation program can be safely implemented in cardiac arrest group which is considered at a high risk group. The exercise capacity can be improved in non-cardiac arrest group with appropriate monitoring. Further study is needed with a larger number of cardiac patients who were resuscitated from cardiac arrest to determine whether our results are universal or conclusive.

\section{CONFLICT OF INTEREST}

No potential conflict of interest relevant to this article was reported. 


\section{REFERENCES}

1. Jacobs I, Nadkarni V, Bahr J, Berg RA, Billi JE, Bossaert $\mathrm{L}$, et al. Cardiac arrest and cardiopulmonary resuscitation outcome reports: update and simplification of the Utstein templates for resuscitation registries: a statement for healthcare professionals from a task force of the International Liaison Committee on Resuscitation (American Heart Association, European Resuscitation Council, Australian Resuscitation Council, New Zealand Resuscitation Council, Heart and Stroke Foundation of Canada, InterAmerican Heart Foundation, Resuscitation Councils of Southern Africa). Circulation 2004;110:3385-97.

2. Zipes DP, Wellens HJ. Sudden cardiac death. Circulation 1998;98:2334-51.

3. Wit AL, Janse MJ. Experimental models of ventricular tachycardia and fibrillation caused by ischemia and infarction. Circulation 1992;85(1 Suppl):I32-42.

4. Nadkarni VM, Larkin GL, Peberdy MA, Carey SM, Kaye W, Mancini ME, et al. First documented rhythm and clinical outcome from in-hospital cardiac arrest among children and adults. JAMA 2006;295:50-7.

5. Eisenberg MS, Mengert TJ. Cardiac resuscitation. N Engl J Med 2001;344:1304-13.

6. Bunch TJ, White RD, Gersh BJ, Meverden RA, Hodge DO, Ballman KV, et al. Long-term outcomes of out-ofhospital cardiac arrest after successful early defibrillation. N Engl J Med 2003;348:2626-33.

7. Cobbe SM, Dalziel K, Ford I, Marsden AK. Survival of 1476 patients initially resuscitated from out of hospital cardiac arrest. BMJ 1996;312:1633-7.

8. Dugmore LD, Tipson RJ, Phillips MH, Flint EJ, Stentiford $\mathrm{NH}$, Bone MF, et al. Changes in cardiorespiratory fitness, psychological wellbeing, quality of life, and vocational status following a 12 month cardiac exercise rehabilitation programme. Heart 1999;81:359-66.

9. Taylor RS, Brown A, Ebrahim S, Jolliffe J, Noorani H, Rees K, et al. Exercise-based rehabilitation for patients with coronary heart disease: systematic review and meta-analysis of randomized controlled trials. Am J Med 2004;116:682-92.

10. O'Connor GT, Buring JE, Yusuf S, Goldhaber SZ, Ol- mstead EM, Paffenbarger RS Jr, et al. An overview of randomized trials of rehabilitation with exercise after myocardial infarction. Circulation 1989;80:234-44.

11. Witt BJ, Jacobsen SJ, Weston SA, Killian JM, Meverden RA, Allison TG, et al. Cardiac rehabilitation after myocardial infarction in the community. J Am Coll Cardiol 2004;44:988-96.

12. American Association of Cardiovascular and Pulmonary Rehabilitation. Guidelines for cardiac rehabilitation and secondary prevention programs. 4th ed. Champaign: Human Kinetics; 2004.

13. Paul-Labrador M, Vongvanich P, Merz CN. Risk stratification for exercise training in cardiac patients: do the proposed guidelines work? J Cardiopulm Rehabil 1999;19:118-25.

14. Law MR, Watt HC, Wald NJ. The underlying risk of death after myocardial infarction in the absence of treatment. Arch Intern Med 2002;162:2405-10.

15. The World Health Report 1997: conquering suffering, enriching humanity. World Health Forum 1997;18:248-60.

16. Balady GJ, Ades PA, Comoss P, Limacher M, Pina IL, Southard D, et al. Core components of cardiac rehabilitation/secondary prevention programs: a statement for healthcare professionals from the American Heart Association and the American Association of Cardiovascular and Pulmonary Rehabilitation Writing Group. Circulation 2000;102:1069-73.

17. Jolliffe JA, Rees K, Taylor RS, Thompson D, Oldridge N, Ebrahim S. Exercise-based rehabilitation for coronary heart disease. Cochrane Database Syst Rev 2001; (1):CD001800.

18. Vanhees L, Stevens A, Schepers D, Defoor J, Rademakers F, Fagard R. Determinants of the effects of physical training and of the complications requiring resuscitation during exercise in patients with cardiovascular disease. Eur J Cardiovasc Prev Rehabil 2004;11:304-12.

19. Thomas RJ, Miller NH, Lamendola C, Berra K, Hedback B, Durstine JL, et al. National Survey on Gender Differences in Cardiac Rehabilitation Programs: patient characteristics and enrollment patterns. J Cardiopulm Rehabil 1996;16:402-12. 